\title{
BMJ Open Cohort profile: a national, population- based cohort of children born after assisted conception in the UK (1992-2009): methodology and birthweight analysis
}

\author{
Mitana Purkayastha (D) , ${ }^{1}$ Stephen A Roberts, ${ }^{2}$ Julian Gardiner (1) ,,3 \\ Daniel R Brison, ${ }^{4}$ Scott M Nelson, ${ }^{5}$ Deborah Lawlor, ${ }^{6}$ Barbara Luke, ${ }^{7}$ \\ Alastair Sutcliffe ${ }^{1}$
}

To cite: Purkayastha M, Roberts SA, Gardiner J, et al. Cohort profile: a national, population-based cohort of children born after assisted conception in the UK (1992-2009): methodology and birthweight analysis. BMJ Open 2021;11:e050931. doi:10.1136/ bmjopen-2021-050931

- Prepublication history and additional supplemental material for this paper are available online. To view these files, please visit the journal online (http://dx.doi.org/10.1136/ bmjopen-2021-050931).

Received 03 March 2021 Accepted 02 July 2021

Check for updates

(C) Author(s) (or their employer(s)) 2021. Re-use permitted under CC BY. Published by BMJ.

For numbered affiliations see end of article.

Correspondence to Dr Mitana Purkayastha; m.purkayastha@ucl.ac.uk

\section{ABSTRACT}

Purpose To generate a large cohort of children born after assisted reproductive technology (ART) in the UK between 1992 and 2009, their naturally conceived siblings (NCS) and matched naturally conceived population (NCP) controls and linking this with health outcome data to allow exploration of the effects of ART. The effects of fresh and frozen embryo transfer on birth weight (BW) were analysed to test the validity of the cohort.

Participants Children recorded on the Human Fertilisation and Embryology Authority (HFEA) register as being born after ART between 1992 and 2009, their NCS and matched NCP controls linked to Office for National Statistics birth registration dataset (HFEA-ONS cohort). This cohort was further linked to the UK Hospital Episode Statistics database to allow monitoring of the child's post-natal health outcomes up to 2015 (HFEA-ONS-HES subcohort). Findings to date The HFEA-ONS cohort consisted of 75348 children born after non-donor ART carried out in the UK between 1 April 1992 and 31 July 2009 and successfully linked to birth registration records, 14763 NCS and 164823 matched NCP controls. The HFEAONS-HES subcohort included 63877 ART, 11343 NCS and 127544 matched NCP controls further linked to health outcome data. The exemplar analysis showed that children born after fresh embryo transfers were lighter (BW difference: $-131 \mathrm{~g}, 95 \% \mathrm{Cl}$ : -140 to -123$)$ and those born after frozen embryo transfers were heavier (BW difference: $35 \mathrm{~g}, 95 \% \mathrm{Cl}: 19$ to 52) than the NCP controls. The withinsibling analyses were directionally consistent with the population control analyses, but attenuated markedly for the fresh versus natural conception (BW difference: -54 g; $95 \% \mathrm{Cl}:-72$ to -36 ) and increased markedly for the frozen versus natural conception (BW difference: $152 \mathrm{~g}$; 95\% Cl: 113 to 190) analyses.

Future plans To use this cohort to explore the relationship between ART conception and short-term and long-term health outcomes in offspring.

\section{INTRODUCTION}

Assisted reproductive technology (ART) usage has increased annually since the first

\section{Strengths and limitations of this study}

- Meticulous linkage of robust, routinely collected administrative health data to yield a large cohort that is nationally unique, thus increasing the generalisability, accuracy and precision of results from subsequent analyses.

- Linkage to the hospital admissions and outpatient database provides long-term mortality and morbidity outcome data on offspring for use in longitudinal research, policy planning and strategic development.

- Identification of naturally conceived siblings as well as matched naturally conceived population controls allows exploration of the association of assisted reproductive technology (ART) with adverse offspring outcomes while accounting for parental factors related to subfertility, which may confound these associations.

- Comparison of findings between the two approaches (ART vs naturally conceived population controls and ART vs naturally conceived siblings) mentioned above increases confidence in findings.

The validity of the cohort was tested by means of an exemplar analysis.

live birth in 1978, with over 8 million children born after ART globally. ${ }^{1}$ This increased utilisation of ART has occurred concurrently with developments in our understanding of the impact of the early life environment on long-term health ${ }^{2-4}$ and most families with ART conceived children reported potential general health risks to their children as their paramount concern, ${ }^{56}$ resulting in a concomitant increase in focus on the potential adverse short-term and long-term effects on offspring.

The inability to distinguish the relative importance of the effects of ART treatment factors and parental subfertility is a common 
limitation of many ART follow-up studies. ${ }^{7-9}$ This issue has been addressed in prospective cohorts by identifying control populations of children born naturally to parents with established subfertility (different from infertility in terms of the time of unwanted non-conception). ${ }^{10}$ One such well-known cohort provided the first evidence of differences in blood pressure and growth parameters in ART children. ${ }^{11}{ }^{12}$ Further evidence comes from within-ART comparisons showing that early life environment (eg, embryo culture medium composition) is associated with changes in fetal growth, birth weight (BW) and child growth, ${ }^{13}{ }^{14}$ and studies of embryo cryopreservation have made a similar point more recently. ${ }^{15}$ These small studies have been essential in both directing and validating the associations identified from large population studies, including prospective cohort studies of ART conceptions only (eg, a Swedish study that followed-up 30959 children born after ART) ${ }^{16}$ or large, record linkage studies (eg, one South Australian record linkage study compared 6163 ART and 302811 naturally conceived (NC) offspring, while another study in Denmark compared 33 139 ART children to 555828 NC children from the population). ${ }^{1718}$ The Committee of Nordic ART and Safety (CoNARTaS), created in 2008, utilised medical registry data from Denmark, Finland, Norway and Sweden to establish a large cohort of children conceived after ART or natural conception as well as women with at least one delivery after ART or natural conception, with the aim of examining long-term health outcomes in children born after ART. ${ }^{19-21}$

While these large studies using conventional multivariable approaches to explore the association of ART with adverse offspring outcomes are essential in order to extrapolate effect sizes and risk estimates to the general ART population, ${ }^{22-24}$ they cannot fully account for parental factors related to subfertility, which may confound these associations. This has been addressed in record linkage studies that used within-sibling analyses (where comparisons are made between ART and their NC siblings) to better control for factors related to subfertility and other family confounders under the assumption that these parental factors would be the same (or very similar) within sibling groups. ${ }^{2325}$ However, such analyses typically have lower statistical power due to restricted numbers and can be biased if there is individual level confounding, and the subset of ART children with siblings may not be representative of the ART population as a whole. Therefore, a comparison of the two approaches is valuable as similar results from both would increase confidence in findings. ${ }^{25-27}$

In the UK, birth rates from in vitro fertilisation treatment have increased by over $85 \%$ since 1991, with around one in three treatment cycles now resulting in a birth for patients under $35 .{ }^{28}$ It has been compulsory for every fertility clinic in the UK to report details of all treatments carried out to the Human Fertilisation and Embryology Authority (HFEA) since its inception in August 1991. ${ }^{29-31}$ Due to the mandatory nature of reporting, the completeness and quality of data related to some couple characteristics (eg, age, duration of infertility) and ART procedures are high, enabling research analysing treatment outcomes including success rates and perinatal outcomes such as gestation, BW and congenital anomalies. ${ }^{32-37}$ However, the quality of perinatal outcome data available on the HFEA register is questionable as it is patient reported via the ART clinics. ${ }^{38}$ Hann et $a l^{39}$ showed that 1 in $15(6 \%)$ BWs recorded on the HFEA register was incorrect compared with data recorded directly by the delivering maternity unit. Moreover, the HFEA register contains no information on the health outcomes of children beyond the immediate perinatal period.

A change in the law in $2009^{40}$ made it possible for researchers to use patient identifying data contained in the HFEA register from 1991 to 2009 for the purpose of linkage to offspring health outcome databases, thus allowing the largest ever population studies of ART childhood cancer ${ }^{41}$ and early child growth. ${ }^{39}$ However, further studies have been limited by extensive data governance requirements and high associated costs, and prospective monitoring of outcomes in this population as they progress from childhood into adulthood has been prevented thus far by the paucity of identifiable information necessary for a variety of linkages.

Consequently, the primary objective of this study was to substantially enhance the research value of the HFEA register by utilising electronic record linkage methodology to establish a cohort of children consisting of those born after ART in the UK between 1992 and 2009, their naturally conceived siblings (NCS) and matched naturally conceived population (NCP) controls to allow exploration of outcomes present on the birth registration dataset and subsequent linkage to other datasets. The secondary objective was to create a subcohort of children born after ART in the UK, NCS and matched NCP controls and linking this with information on their postnatal health outcomes up to 2015. These databases will be made available to all researchers (subject to necessary approvals), allowing more precise risk estimates of associations of ART with many potential childhood (and maternal) outcomes. Finally, the third objective of this study was to validate the cohort and subcohort produced by comparing the effects of fresh and frozen embryo transfer versus natural conception on singleton BW. The hypothesis being tested was that children born after frozen embryo transfers would be heavier and those born after fresh embryo transfers would be lighter than those that were NC. Our previous linkage from the HFEA 1991-2009 cohort to maternity and child growth records confirmed evidence in the field that children born after frozen embryo transfers are heavier and those born after fresh embryo transfers are lighter than those that are $\mathrm{NC}$ and that these differences in BW are further associated with differences in child growth up to the age of $5 .{ }^{39}$ However, this study was only able to examine the subset of ART children born in Scotland and the dataset created was not readily linkable to other datasets. 
COHORT DESCRIPTION

\section{Databases used}

Human Fertilisation and Embryology Authority Register

The HFEA, an 'arm's length body' of the Department of Health, acts as an independent regulator of fertility treatment and research using human embryos in the UK. ${ }^{31}$ All licensed fertility clinics in the UK are required by law to provide information to the HFEA about treatments they carry out and their outcomes, ensuring high levels of data completeness. Only 1500 ART outcomes had not been reported as of $07 / 01 / 2020$, almost all of which were likely to be from overseas patients who had ART in the UK and returned home for the delivery making it difficult for clinics to follow-up. ${ }^{42}$ Regular quality assurance checks including manual validation of data submissions; regular quality assurance checks on data through the inspection process; publication of non-compliances with data quality issues in inspection reports and, where relevant, review of quality reports and auditing of clinics with irregular data submissions are also carried out. ${ }^{43}$

The HFEA Act $1990^{29}$ made prospective collection and storage of baseline information and birth outcomes on the HFEA register mandatory, although 'consent for disclosure of information for research' was not collected from patients who underwent treatment at a licensed fertility clinic prior to September 2009. The reliability and completeness of information relating to women who have undergone treatment on the HFEA register are considerably high (approximately 99.9\%, 100\%-99.9\% completeness for forename, surname and DOB, respectively; online supplemental table S1), although it contains little identifiable information on children born after ART (eg, $11.2 \%$ and $10.3 \%$ completeness for child's surname and forename, respectively; online supplemental table S1).

Details of the data accessed from HFEA for this study are discussed below (see Linkage section).

\section{Birth Registration Database}

In the UK, all births are legally required to be registered by the Local Registration Service in partnership with the General Register Office (GRO) in England and Wales, making it the most complete data source available. ${ }^{44}$ The birth registration dataset is managed by ONS in England and Wales, while Scottish birth records are held by National Records for Scotland (NRS) who work closely with NHS Digital to ensure daily record transfers between the organisations using a secure and closed electronic system.

This study used the birth registration dataset to identify all children born to women known to have undergone ART as well as their NCS, and details of the data accessed have been discussed below (see Linkage section).

\section{Hospital Episode Statistics}

Hospital Episode Statistics (HES) is a data warehouse containing details of all admissions, outpatient appointments and A\&E attendances at NHS hospitals in England. ${ }^{45}$
HES data covers all NHS Clinical Commissioning Groups (CCGs) in England, including private patients treated in NHS hospitals, patients resident outside of England, and care delivered by treatment centres (including those in the independent sector) funded by the NHS. ${ }^{45}$ Approximately $98 \%-99 \%$ of hospital activity in England are estimated to be funded by the NHS. ${ }^{46}$ Moreover, the HES admitted patient care (APC) database covers all births in NHS hospitals, representing approximately $97.3 \%$ of births in England, thus enabling creation of nationally representative birth cohorts. ${ }^{47} 48$

Although the HES data warehouse has been operating since $1990,{ }^{49}$ linkage of the HES APC episodes longitudinally to the same individuals only commenced in 1997/98 when the patient's NHS number became a mandated return from hospitals. ${ }^{48}$ Furthermore, linkage of this APC dataset to other HES datasets such as outpatient, A\&E and adult critical care only commenced much later in 2003/2004, 2007/2008 and 2008/2009, respectively. ${ }^{48}$ HES diagnoses were coded using the International Classification of Diseases version 9 (ICD-9) between April 1989 and March 1995 and ICD-10 thereafter.

This study linked the HES database to the ART children, NCS and matched NCP control groups, and the data accessed for this purpose have been discussed below (see Linkage section). Although the current paper only uses demographic data (ethnicity; UK census-derived Index of Multiple Deprivation (IMD), the official measure of relative deprivation for small areas or neighbourhoods in the $\mathrm{UK}^{50}$ ) and BW from HES to carry out an exemplar analysis, further analyses of longitudinal health outcomes in these cohorts are already underway and will be published shortly.

\section{Medical Integrated Database and Administration System}

MIDAS is a system used by NHS Digital's Data Linkage and Extract Service (DLES) to replace the functionality previously provided by the Central Health Register Information System (CHRIS) application, specifically for the administration of information used within research and data linkage functions. It was developed to provide continuity for the existing list cleaning, flagging, tracing and cohort management services to maintain support for approved research and audit projects, National Cancer Registration and the ONS Longitudinal Study. It contains up to date demographic GP registration data via a daily feed from the Secondary User Service, standard demographic identifiers such as names and addresses, information on patients who have exited from and returned to the NHS, as well as cancer and death registration details. MIDAS can be considered as a window into the Personal Demographics Service database, providing bespoke data extracts in addition to regular patient tracking services. Extracts are provided on an individual as-and-when basis and are subject to the regular DLES approvals process.

In this study, the cohort produced by Linkage 1 (discussed later) was traced on MIDAS for further demographic information (NHS number where necessary, 
postcode, etc) that would allow subsequent linkage to HES. Additionally, the matched NCP controls were also identified using MIDAS.

\section{Inclusion and exclusion criteria}

ART: defined as 'treatments or procedures that include in vitro handling of both human oocytes and sperm or embryos, for the purpose of reproduction'. ${ }^{51}$ This study included all children born after non-donor ART conducted in the UK between 1 April 1992 and 31July 2009, in keeping with legislative changes that influenced the ability to link HFEA data to other health datasets. ${ }^{39} 41$ It was estimated that only $0.2 \%$ of patients receiving ART during the study period retrospectively withdrew consent. $^{52}$

NCS: All NC children born to women with at least one child born following ART were included. This comprised of both full (both parents the same) and maternal halfsiblings (same mother different father), but identification of paternal half-siblings was not possible.

NCP controls: The birth registration dataset and MIDAS were used to identify two matched (by month and year of birth, sex and multiplicity/plurality) NCP controls per ART child (ART: control=1:2).

All children conceived in the UK after ART but born outside of England, Wales and Scotland, those born after ART to women who permanently lived outside the UK but travelled to the UK for ART treatment and those born in Northern Ireland were excluded as it would not be possible to link them to ONS birth records. Additionally, siblings born outside of the study period (as their conception status could not be verified) as well as those born outside of England, Wales and Scotland were also excluded. Cases that had withdrawn consent for their data to be used for research and children born after donor ART were excluded in compliance with HFEA legislation that prevents the viewing of identifiable data relating to these children by any third party.

\section{Linkage}

As described above, the HFEA Register contains very few identifiers for children born after ART, thus limiting linkage to other nationally held datasets. Therefore, this study initially linked HFEA records of children born to women known to have undergone ART to nationally held birth records to add identifiers and NHS numbers, which would enable further linkage with a variety of other datasets (shown in figures 1 and 2).

\section{Linkage 1: HFEA-ONS}

Step 1 (1 and 2 from figure 1): The HFEA first identified children born after ART and assigned them pseudoanonymised unique record numbers (URN). Maternal unique record numbers (mURN; created from a previous study ${ }^{52}$ online supplemental table S2) were added to the file, which was encrypted and sent securely to NHS Digital.

This file contained the following variables: date of birth (DOB) of child, BW of child, sex of child, forename of mother, surname of mother, previous name(s) of mother, multiplicity/plurality (eg, singleton, twin), and mother's DOB.

Step 2 (3 and 4 from figure 1): NHS Digital created file 2 (from a previous study ${ }^{52}$; online supplemental table S2) containing extracts of women who had undergone ART within the specified time period and securely transferred it to ONS. This file contained the NHS Number, DOB of possible mother, surname of possible mother, forename of possible mother, other name(s) of possible mother, and the HFEA mURN.

ONS then used these variables to link to birth records to create an extract of all children born to these mothers within the specified time frame. This extract (File 3) contained the mothers' details as supplied in File 2, surname of the child, forename of the child, DOB of the child, NHS number of the child (if available), BW of the child and sex of the child. This file was then securely transferred back to NHS Digital.

Step $3(5,6,7,8$ and 9 from figure 1): NHS Digital then matched files 1 and 3 to determine children born to these mothers after ART and their NCS. This linkage was carried out using DOB of child, NHS number of child (if available), BW of child, sex of child, surname of child (where available on HFEA file 1) and forename of child (where available on HFEA file 1).

The ART and sibling cohorts were then traced using NHS Digital's national Medical Integrated Database and Administration System (MIDAS) to update demographic information (including NHS number, postcode) and current status (emigrations/deaths, etc) and allow subsequent linkage to medical records.

Step 4 (10 and 11 from figure 1): NHS Digital used MIDAS to identify two controls for every cohort member, matched for month and year of birth, sex and multiplicity/plurality (singleton/ multiple birth).

Step 5 (14 from figure 1): NHS Digital produced updated demographic information on all ART children, siblings and controls (as obtained from MIDAS) and provided de-identified outputs plus non-identifiable deprivation scores to the research team at University College London (UCL).

\section{Linkage 2: HFEA-ONS-HES}

Step 6 (15 on figure 2): NHS Digital then linked all cohorts produced by linkage 1 to HES using NHS number, postcode and DOB and shared with the research team at UCL.

Step 7 (16 on figure 2): HFEA staff extracted relevant anonymised fertility data and this was shared with the research team at UCL who linked these two files (from steps 6 and 7) using the URNs.

Step 8 (17 on figure 2): For the purpose of this second linkage, UCL researchers excluded records of children born before 1 April 1997 to coincide with the start of HES monitoring as well as triplets and higher order births from all groups (along with associated ART and NC births) to produce the final cohorts for health outcome analysis. 


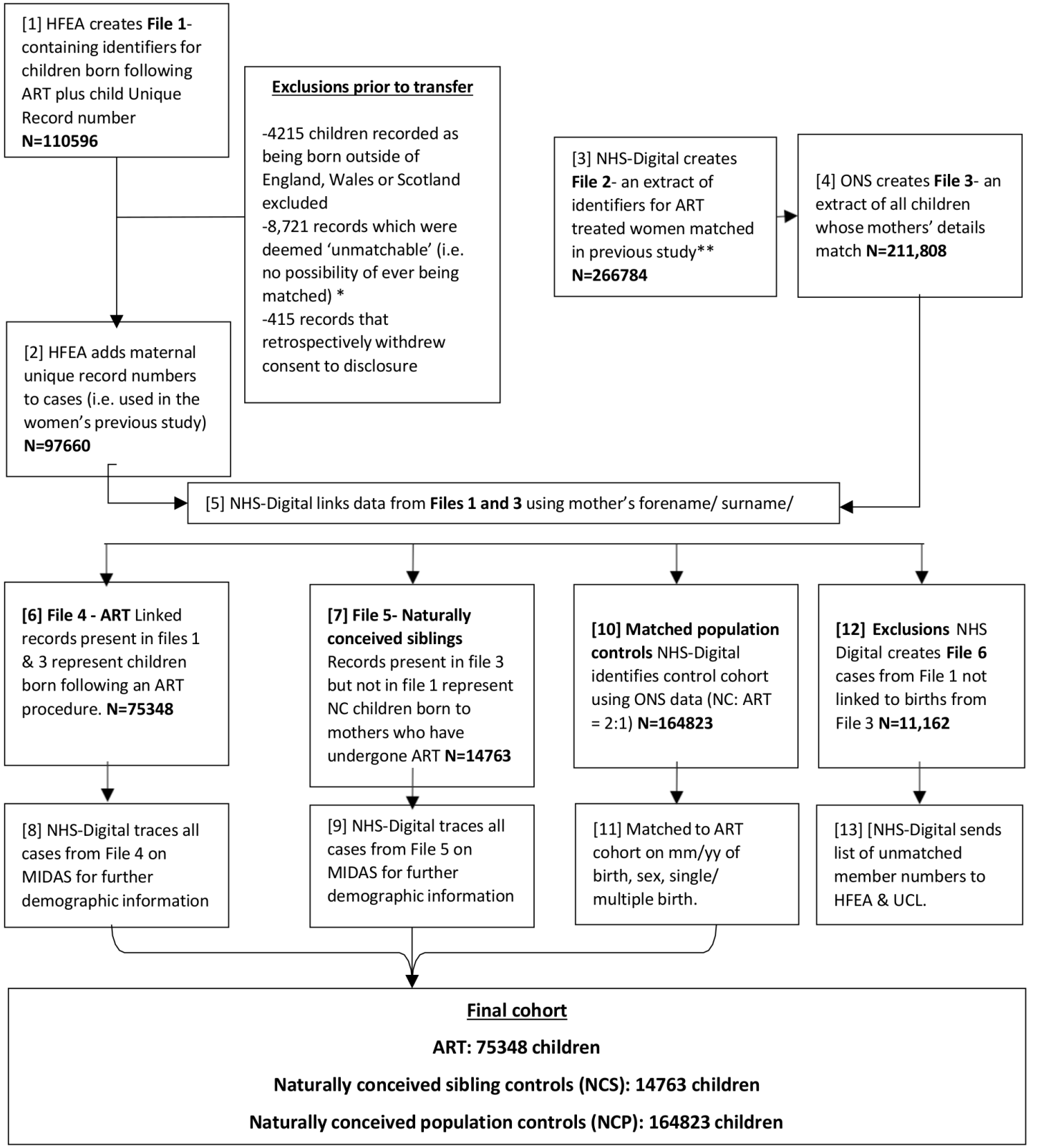

*as they were a) births outside of England/ Wales; b) births before 1993 (when ONS systems were automated and thus the date from which linkage is possible to ONS records); and c) to mothers which were not included in file 2 (as it was not possible to identify them on NHS-Digital systems previously- 'women's study').

** Please see Supplementary figure $\mathrm{S} 2$ for cohort flow

Figure 1 Flowchart showing linkage 1 (HFEA-ONS). *As they were (a) births outside of England/ Wales; (b) births before 1993 (when ONS systems were automated and thus the date from which linkage is possible to ONS records) and (c) to mothers which were not included in file 2 (as it was not possible to identify them on NHSDigital systems previously - 'women's study'). ${ }^{* *}$ Please see online supplemental figure S2 for cohort flow. ART, assisted reproductive technology; HFEA, Human Fertilisation Embryology Authority; NC, naturally conceived; ONS, Office for National Statistics.

Step 9 (18 on figure 2): NHS Digital produced file 4 (shown in figure 1) for the ART and NC cohorts and these are now securely stored at HFEA and NHS Digital, respectively.

The entire linkage process was completed by NHS Digital and none of the researchers had access to any identifiable participant data. The details of the ART and NC groups were encrypted and are currently held securely at HFEA and NHS Digital, respectively.

\section{Cohorts produced}

Linkage 1: HFEA-ONS cohort

1. ART: This group consisted of all children born after non-donor ART conducted in the UK between 1 April 1992 and 31st July 2009.

2. NCS: This included all NC children born to women who had at least one child born following ART. This included full and maternal half-siblings but not paternal half-siblings. 


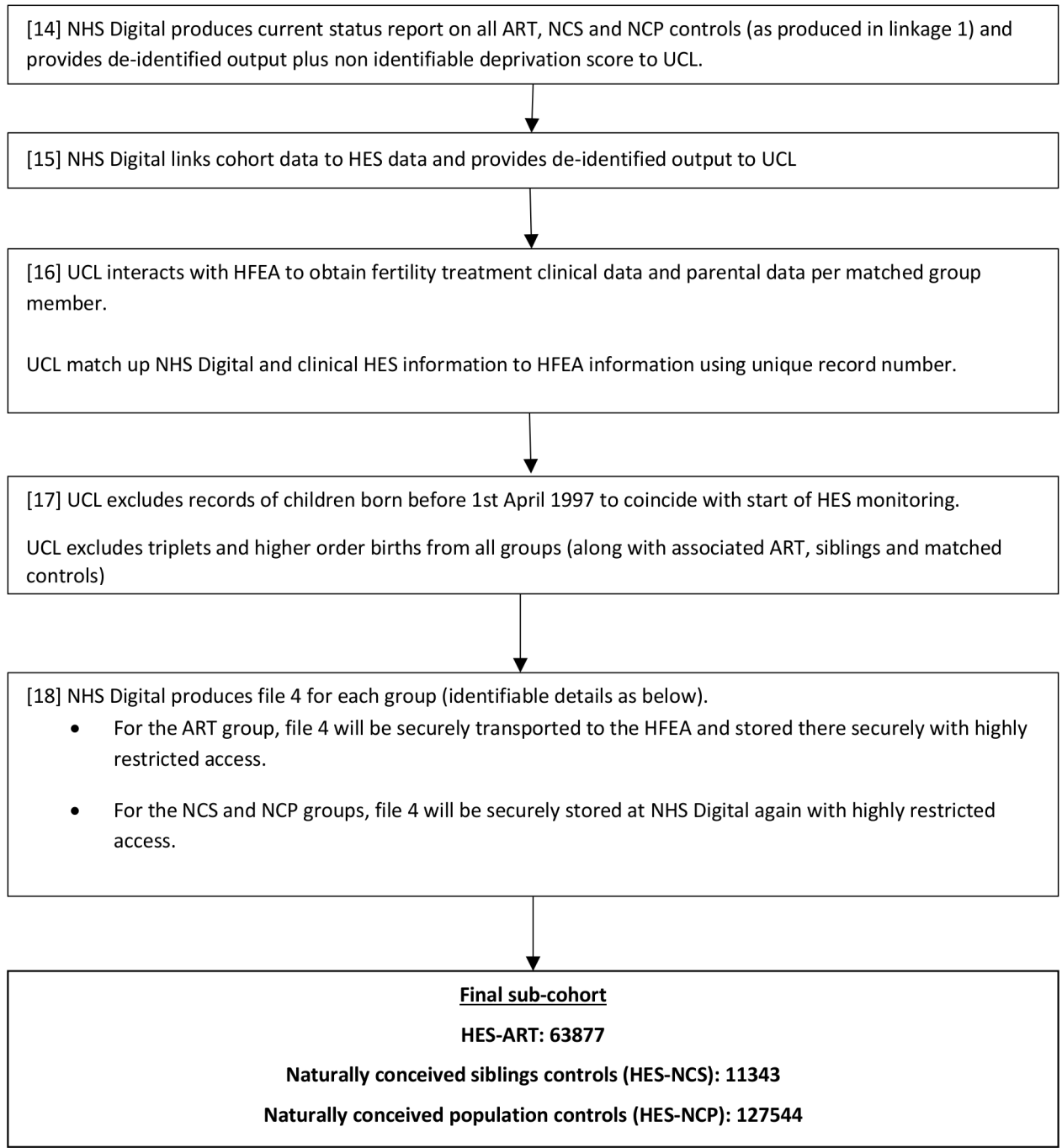

Figure 2 Flowchart showing linkage 2 (HFEA-ONS-HES). ART, assisted reproductive technology; HES, Hospital Episode Statistics database; HFEA, Human Fertilisation and Embryology Authority; UCL, University College London.

3. NCP: This consisted of two matched (by month and year of birth, sex and multiplicity/plurality) NCP controls for each ART child.

\section{Linkage 2: HFEA-ONS-HES subcohort}

1. ART with HES outcomes (HES-ART): This included all children born after non-donor ART conducted in the UK between 1 April 1997 and 31 July 2009 linked to their HES outcomes.

2. NCS with HES outcomes (HES-NCS): This included the NCS of all non-donor ART children born in the UK between 1 April 1997 and 31 July 2009 linked to their HES outcomes.

3. NCP control with HES outcomes (HES-NCP): This included two matched NCP controls for each non-donor ART child born in the UK between 1 April 1997 and 31 July 2009 linked to their HES outcomes.

\section{Data cleaning}

Data cleaning included deletion of triplets and higher order births along with their NCS and matched NCP controls; deletion of duplicates; and reformatting, labelling and creation of new variables. Triplets and higher order births were excluded from analysis as they are known to be associated with adverse perinatal outcomes such as higher infant mortality, birth defects, premature birth and low BW. ${ }^{53}$ Initial data scoping also revealed several discrepancies in the data, a common limitation of large data linkage studies utilising multiple data sources, and pragmatic rules were employed to derive a consensus. Additional data cleaning carried out on the subcohort produced via linkage 2 included creation of an additional group consisting of ART children who had NCS (HESsART) for the purposes of analysis. Order of pregnancy was calculated by sorting the child DOBs within each family in ascending order (online supplemental table S3), and the type of ART and cause of infertility variables were regrouped appropriately.

\section{Exemplar analysis}

An exemplar analysis examining the effect of fresh and frozen embryo transfer (each compared with NC) on singleton BW was carried out using the HFEA-ONS 
cohort and HFEA-ONS-HES subcohort (inclusion criteria discussed previously). Details of BW are provided by the hospital where the birth took place or by the midwife/ doctor in attendance at the birth and is then passed to ONS as a consequence of the NHS birth notification being linked to the corresponding birth registration by the registrar. Multiple regression analysis was used to compare BW between children born after ART and NCP controls. The models were adjusted for maternal age at delivery and sex for the ART versus NCP analysis and for maternal age at delivery, sex, IMD at earliest appointment and ethnicity for the HES-ART vs HES-NCP analysis.

A family-matched model was used to compare BW between ART children and their NCS, including a family covariate to allow for within family correlations. The models were adjusted for maternal age at delivery, sex and order of pregnancy. IMD and ethnicity were excluded from this analysis as the underlying effects they represent would have remained constant within families. The models were parameterised to directly estimate the differences between ART (fresh and frozen) and NC children. The fresh versus frozen difference was estimated from the model by construction of the appropriate contrast. All analyses were carried out using Stata V.16.0.

This paper was developed in accordance with the STROBE reporting guidelines. ${ }^{55}$

\section{Patient and public involvement}

No patients involved. Due to the very personal nature of the treatments involved, it was not appropriate to contact the families directly, thus preventing us from involving patients or the public in the design, conduct, reporting, or dissemination plans of our research.

\section{FINDINGS TO DATE}

\section{Final HFEA-ONS cohort}

The HFEA identified 110596 children that met our inclusion criteria, of which 97660 (figure 1) were deemed suitable for transfer to NHS Digital and subsequent linkage to ONS birth records. The linkage success rate was $77 \%$ (75 348 cases out of 97660 ) due to the poor quality of data received from the HFEA.

A feasibility pilot study testing the validity of the linkage carried out in this study showed that the false positivity rates were very low $(<0.0002 \%$, unpublished data). Matching was done using SQL using exact matching (design to be inclusive of all potential matches) followed by probabilistic matching using Jaro Winkler software. A clash was defined as a complete incompatibility of information between databases for a particular variable, with no clashes deemed as being a match. The HFEA were asked for further information in case of one clash, and more than one clash was considered to be a failed match. In the current study, the main linkage was carried out using a very high threshold for matching, and the weak/ inaccurate identifiers in the HFEA register often resulted in matches that failed to pass this threshold. The majority of unlinked records could not be found due to clashes in parental identifiers and child date of birth.

As the main linkage carried out in this study was bespoke in nature, particularly with regard to identification of the NC siblings, and had not been carried out before, standardised quality assurance measures could not be applied and instead extensive manual checking of the linkage was implemented. However, due to the mandatory nature of reporting all ART cycles carried out in the UK to the HFEA, it is unlikely that the unlinked records differed significantly from those that were linked, thus minimising the risk of selection bias.

Tables 1 and 2 show the descriptive characteristics of the final HFEA-ONS cohort generated after completion of Linkage 1 (figure 1) and data cleaning. This cohort included 75348 children born after ART between 1992 and 2009 and 164823 matched NCP controls. Of the children born after ART, 15875 (sART) had 14763 NCS and the majority of families had had an ART pregnancy first followed by natural conception (online supplemental table S3).

The majority of the final cohort were ethnically white and singleton births, and a greater proportion of the ART and NCS groups were from a higher socioeconomic class. The majority of women who underwent ART were aged between 30 and 39 years at the time of delivery, while those with NC births tended to be slightly younger (25-39 years).

\section{Final HFEA-ONS-HES sub-cohort}

All births before 1 April 1997 were excluded for the purpose of linkage to HES, resulting in 63877, 11343 and 127544 children in the HES-ART, HES-NCS and HES-NCP groups, respectively. Linkage 2 (figure 2) had a success rate of $84.7 \%$, and the descriptive characteristics of the sub-cohort produced have been shown in tables 2 and 3

\section{Exemplar analysis: singleton BW}

The exemplar analysis included all singleton births in the HFEA-ONS cohort and HFEA-ONS-HES subcohort.

HFEA-ONS: Comparing ART to NCP showed that children born after fresh embryo transfers were lighter (BW difference: -131 g; 95\% CI: -140 to -123 ) and those born after frozen embryo transfers were heavier (BW difference: 35 g; 95\% CI: 19 to 52) than the NC controls (table 4; online supplemental table S4). Moreover, children born after frozen embryo transfers were significantly heavier than those born after fresh embryo transfers (BW difference: -167 g; 95\% CI: -183 to -150$)$.

Family-matched analysis showed that children born after fresh embryo transfers were lighter (BW difference: -54 g; $95 \%$ CI: -72 to -36 ) and those born after frozen embryo transfers (BW difference: 138 g; 95\% CI: 101 to 175) were heavier than the NCS group (table 4; online supplemental table S5). Moreover, children born after frozen embryo transfers were significantly heavier than 
Table 1 Demographic characteristics of art children, NCS and matched NCP controls born between 1 April 1992 and 31 July 2009

\begin{tabular}{|c|c|c|c|c|}
\hline & \multicolumn{4}{|c|}{ HFEA-ONS cohort } \\
\hline & ART & Control (NCP) & ART with siblings (sART) & Siblings (NCS) \\
\hline Infants & 75348 & 164823 & 15875 & 14763 \\
\hline \multicolumn{5}{|c|}{ Mean BW (SD) } \\
\hline Singleton & $3282.0(620.3)$ & $3353.83(578.5)$ & $3311.12(605.1)$ & $3430.05(581.9)$ \\
\hline Multiple & $2378.3(593.4)$ & $2340.28(626.1)$ & $2405.10(608.1)(638.36)$ & $2292.03(780.5)$ \\
\hline \multicolumn{5}{|l|}{ Sex } \\
\hline Female & 36994 (49.1\%) & 80859 (49.1\%) & 7598 (47.9\%) & $7271(49.3 \%)$ \\
\hline Male & 38354 (50.9\%) & 83964 (50.9\%) & $8277(52.1 \%)$ & $7492(50.8 \%)$ \\
\hline \multicolumn{5}{|c|}{ Multiplicity/plurality } \\
\hline Singleton & $44488(59.1 \%)$ & $99554(60.4 \%)$ & $10592(66.7 \%)$ & $14055(95.2 \%)$ \\
\hline Twin & 30860 (40.9\%) & 65269 (39.6\%) & $5283(33.3 \%)$ & $708(4.8 \%)$ \\
\hline \multicolumn{5}{|c|}{ Maternal age group (years) } \\
\hline$<25$ & $731(0.1 \%)$ & $33156(20.1 \%)$ & $256(1.6 \%)$ & $388(2.6 \%)$ \\
\hline $25-29$ & $5315(7.1 \%)$ & $30231(18.3 \%)$ & $1326(8.4 \%)$ & $1032(6.1 \%)$ \\
\hline $30-34$ & $23342(30.1 \%)$ & $46050(27.9 \%)$ & $5466(34.4 \%)$ & $3855(26.1 \%)$ \\
\hline $35-39$ & $29187(38.7 \%)$ & 30345 (18.4\%) & $5872(36.1 \%)$ & $5711(38.7 \%)$ \\
\hline $40-44$ & 8705 (11.6\%) & $7812(4.7 \%)$ & $1315(8.3 \%)$ & 2157 (14.6\%) \\
\hline$\geq 45$ & $84(0.1 \%)$ & $587(0.4 \%)$ & $23(0.1 \%)$ & $53(0.4 \%)$ \\
\hline Missing & 7984 (10.6\%) & $16642(10.1 \%)$ & $1617(10.2 \%)$ & $1567(10.6 \%)$ \\
\hline \multicolumn{5}{|l|}{ Birth year } \\
\hline 1992 & $57(0.1 \%)$ & $131(0.1 \%)$ & $12(0.08 \%)$ & $23(0.2 \%)$ \\
\hline 1993 & $1595(2.1 \%)$ & 3187 (1.9\%) & 299 (1.8\%) & 337 (2.3\%) \\
\hline 1994 & 2021 (2.7\%) & 4029 (2.4\%) & 425 (2.7\%) & 389 (2.6\%) \\
\hline 1995 & 2439 (3.2\%) & $4911(2.1 \%)$ & 518 (3.3\%) & $526(3.6 \%)$ \\
\hline 1996 & 2977 (3.1\%) & 5989 (3.6\%) & $641(4.0 \%)$ & 577 (3.9\%) \\
\hline 1997 & 3574 (4.7\%) & 7172 (4.4\%) & 776 (4.9\%) & $679(4.6 \%)$ \\
\hline 1998 & 3826 (5.1\%) & 7670 (4.7\%) & 861 (5.4\%) & 800 (5.4\%) \\
\hline 1999 & $4253(5.6 \%)$ & 8531 (5.2\%) & $1023(6.4 \%)$ & 804 (5.5\%) \\
\hline 2000 & 4504 (5.1\%) & 9106 (5.5\%) & 1119 (7.1\%) & 961 (6.5\%) \\
\hline 2001 & $4754(6.3 \%)$ & 9677 (5.9\%) & $1163(7.3 \%)$ & 991 (6.7\%) \\
\hline 2002 & 5149 (6.8\%) & $10464(6.4 \%)$ & 1339 (8.4\%) & 999 (6.8\%) \\
\hline 2003 & $5531(7.3 \%)$ & $11373(6.9 \%)$ & $1401(8.8 \%)$ & $1064(7.2 \%)$ \\
\hline 2004 & 5671 (7.5\%) & $11835(7.2 \%)$ & 1379 (8.7\%) & 1098 (7.4\%) \\
\hline 2005 & 5768 (7.7\%) & $12310(7.5 \%)$ & 1372 (8.6\%) & 1109 (7.5\%) \\
\hline 2006 & 6331 (8.4\%) & $14248(8.6 \%)$ & $1273(8.0 \%)$ & $1116(7.6 \%)$ \\
\hline 2007 & $6410(8.5 \%)$ & $15976(9.7 \%)$ & 1126 (7.1\%) & $1209(8.9 \%)$ \\
\hline 2008 & 6395 (8.5\%) & 17222 (10.5\%) & 719 (4.5\%) & $1271(8.6 \%)$ \\
\hline 2009 & $4092(5.4 \%)$ & $10992(6.7 \%)$ & $429(2.7 \%)$ & $810(5.5 \%)$ \\
\hline
\end{tabular}

ART, assisted reproductive technology; BW, birth weight; HFEA, Human Fertilisation and Embryology Authority; NCP, naturally conceived population controls; NCS, naturally conceived siblings; ONS, Office for National Statistics; sART, ART with siblings.

those born after fresh embryo transfers (BW difference $=-193 \mathrm{~g} ;$ 95\% CI: -232 to -154$)$.

HFEA-ONS-HES: Comparing HES-ART to HES-NCP showed that children born after fresh embryo transfers were lighter (BW difference: -152 g; 95\% CI: -162 to -142) and those born after frozen embryo transfers were similar in weight (BW difference: 3 g; $95 \%$ CI: -17 to 22) to the NC controls (table 4; online supplemental table 
Table 2 Fertility characteristics of ART children by cohort

HFEA-ONS cohort

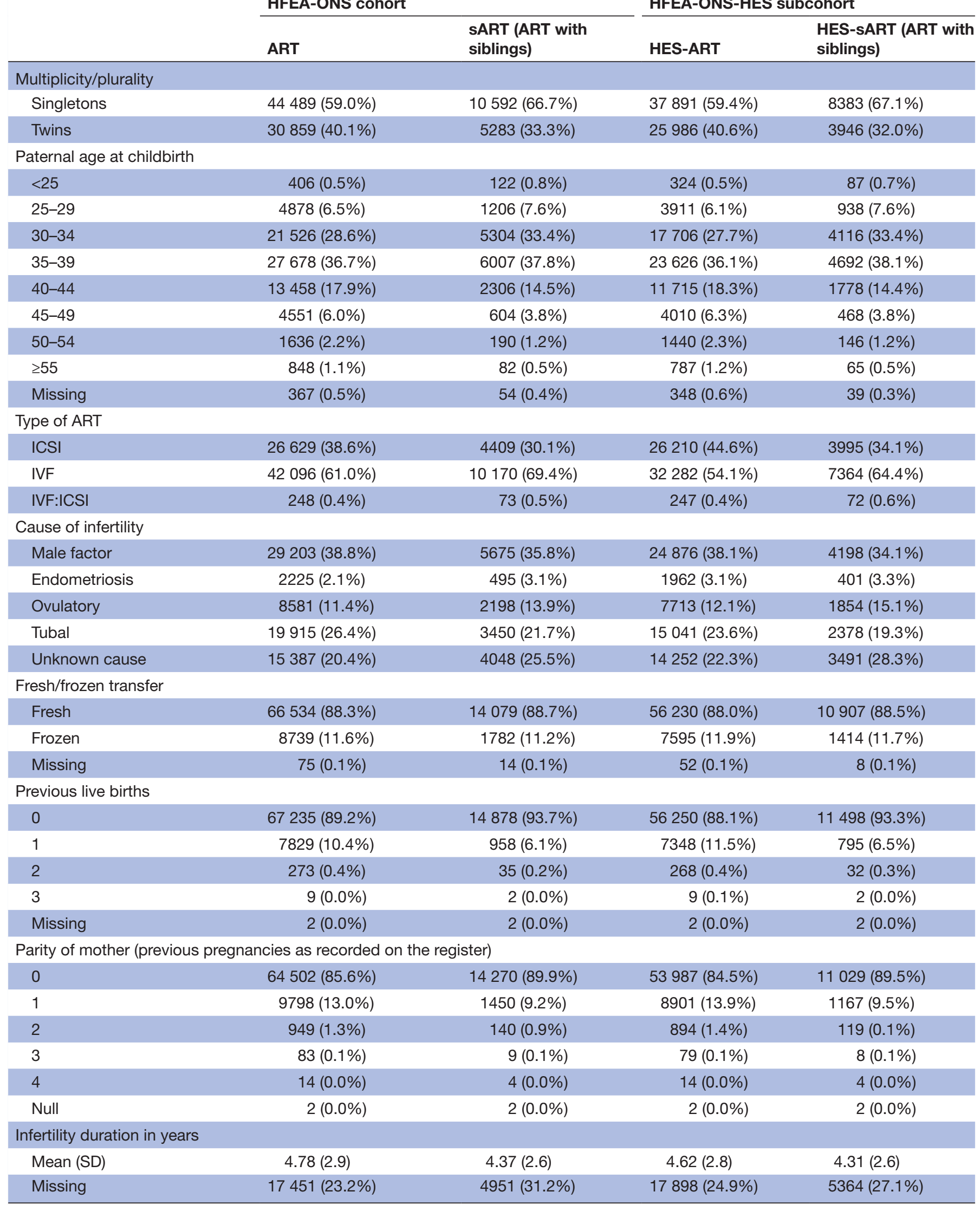

ART, assisted reproductive technology; HES, Hospital Episode Statistics; HFEA, Human Fertilisation and Embryology Authority; ICSI, intracytoplasmic sperm injection; IVF, in vitro fertilisation; ONS, Office for National Statistics; sART, ART with siblings. 
Table 3 Demographic characteristics of ART children, NCS and matched NCP controls born between 1 April 1997 and 31 July 2009

HFEA-ONS-HES subcohort

HES-ART

Control (HES-NCP)

ART with siblings (HES-SART)

Siblings (HES-NCS)

Infants

63877

127544

12329

11343

Follow-up period in days

\begin{tabular}{|c|c|c|c|c|}
\hline Median (IQR) & 4429 (2181) & 4409 (2141) & 4635 (1846) & 4307 (2029) \\
\hline \multicolumn{5}{|l|}{ Mean BW (SD) } \\
\hline Singleton & 3166.95 (742.3) & 3271.67 (648.5) & 3222.25 (699.3) & 3346.54 (712.0) \\
\hline Multiple & 2172.27 (715.4) & 2155.77 (683.9) & 2201.58 (724.9) & $2301.17(677.8)$ \\
\hline \multicolumn{5}{|l|}{ Sex } \\
\hline Female & 31435 (49.2\%) & 62785 (49.2\%) & 5907 (47.9\%) & $5573(49.1 \%)$ \\
\hline Male & 32442 (50.8\%) & 64759 (50.8\%) & $6422(52.1 \%)$ & 5770 (50.9\%) \\
\hline \multicolumn{5}{|l|}{ Multiplicity/plurality } \\
\hline Singleton & 37890 (59.4\%) & 75642 (59.3\%) & 8383 (68.0\%) & 10815 (95.8\%) \\
\hline Twin & 25987 (40.6\%) & $51902(40.7 \%)$ & 3946 (31.1\%) & $528(4.2 \%)$ \\
\hline \multicolumn{5}{|l|}{$\begin{array}{l}\text { IMD decile at earliest } \\
\text { appointment }\end{array}$} \\
\hline 1 (most deprived) & $2045(3.2 \%)$ & $12696(9.9 \%)$ & 349 (2.8\%) & $299(2.6 \%)$ \\
\hline 2 & $2650(4.2 \%)$ & 11104 (8.7\%) & $458(3.7 \%)$ & $396(3.5 \%)$ \\
\hline 3 & 3311 (5.2\%) & 10057 (7.8\%) & 539 (4.4\%) & 463 (4.1\%) \\
\hline 4 & $3926(6.1 \%)$ & $9550(7.5 \%)$ & $678(5.4 \%)$ & $588(5.2 \%)$ \\
\hline 5 & 4666 (7.2\%) & $9161(7.5 \%)$ & $862(6.1 \%)$ & 746 (6.6\%) \\
\hline 6 & $5350(8.4 \%)$ & $8872(6.5 \%)$ & $1084(8.8 \%)$ & $921(8.1 \%)$ \\
\hline 7 & 6142 (9.6\%) & 8842 (6.9\%) & 1205 (9.8\%) & 1044 (9.2\%) \\
\hline 8 & 6675 (10.5\%) & $8925(7.0 \%)$ & $1299(10.5 \%)$ & $1161(10.3 \%)$ \\
\hline 9 & 7729 (12.1\%) & $9083(7.1 \%)$ & 1557 (12.6\%) & $1386(12.2 \%)$ \\
\hline 10 (least deprived) & 7710 (12.1\%) & $8299(6.5 \%)$ & $1720(14.0 \%)$ & 1499 (13.3\%) \\
\hline Missing & 13673 (21.4\%) & 30955 (24.3\%) & 2580 (20.9\%) & $2840(25.0 \%)$ \\
\hline \multicolumn{5}{|l|}{ Birth year } \\
\hline 1997 & $2597(4.1 \%)$ & $5160(4.1 \%)$ & $518(4.2 \%)$ & $242(2.1 \%)$ \\
\hline 1998 & $3708(5.8 \%)$ & $7389(5.9 \%)$ & $743(6.0 \%)$ & $419(3.7 \%)$ \\
\hline 1999 & $4083(6.4 \%)$ & $8126(6.5 \%)$ & 852 (6.9\%) & 560 (4.9\%) \\
\hline 2000 & $4310(6.8 \%)$ & $8633(6.9 \%)$ & 925 (7.5\%) & $781(6.9 \%)$ \\
\hline 2001 & 4559 (7.1\%) & $9160(7.3 \%)$ & 972 (7.9\%) & $879(7.78 \%)$ \\
\hline 2002 & $4980(7.8 \%)$ & $9933(7.9 \%)$ & $1171(9.5 \%)$ & 937 (8.3\%) \\
\hline 2003 & $5379(8.4 \%)$ & 10788 (8.5\%) & 1253 (10.2\%) & 1012 (8.9\%) \\
\hline 2004 & $5561(8.7 \%)$ & $11082(8.7 \%)$ & $1271(10.3 \%)$ & 1067 (9.4\%) \\
\hline 2005 & 5662 (8.9\%) & 11326 (8.8\%) & 1271 (10.3\%) & 1078 (9.5\%) \\
\hline 2006 & $6275(9.8 \%)$ & $12513(9.7 \%)$ & $1217(9.7 \%)$ & $1100(9.7 \%)$ \\
\hline 2007 & 6342 (9.9\%) & 12701 (9.8\%) & 1058 (8.6\%) & 1199 (10.6\%) \\
\hline 2008 & 6347 (9.9\%) & $12718(9.8 \%)$ & $670(5.4 \%)$ & $1260(11.1 \%)$ \\
\hline 2009 & 4074 (6.4\%) & 8015 (6.2\%) & 408 (3.3\%) & 809 (7.1\%) \\
\hline \multicolumn{5}{|l|}{ Ethnicity } \\
\hline White & 61921 (96.9\%) & $122050(95.7 \%)$ & 11983 (97.2\%) & 11084 (97.7\%) \\
\hline Asian/Asian British & 959 (1.5\%) & $2496(1.1 \%)$ & 197 (1.6\%) & $153(1.4 \%)$ \\
\hline Chinese & $35(0.1 \%)$ & $89(0.1 \%)$ & $8(0.1 \%)$ & $1(0.0 \%)$ \\
\hline
\end{tabular}

Continued 


\begin{tabular}{|c|c|c|c|c|}
\hline & \multicolumn{4}{|c|}{ HFEA-ONS-HES subcohort } \\
\hline & HES-ART & Control (HES-NCP) & $\begin{array}{l}\text { ART with siblings } \\
\text { (HES-sART) }\end{array}$ & Siblings (HES-NCS) \\
\hline Mixed/multiple ethnic groups & $318(0.5 \%)$ & $721(0.6 \%)$ & $38(0.3 \%)$ & $27(0.2 \%)$ \\
\hline$\leq 25$ & $710(1.1 \%)$ & $27783(21.9 \%)$ & $241(1.1 \%)$ & $317(2.9 \%)$ \\
\hline $25-29$ & $5085(7.1 \%)$ & 25115 (19.7\%) & 1209 (9.9\%) & $887(7.8 \%)$ \\
\hline $30-34$ & $21994(34.4 \%)$ & $38896(30.5 \%)$ & 4797 (38.9\%) & $3309(29.1 \%)$ \\
\hline $35-39$ & $27682(43.4 \%)$ & 25907 (20.3\%) & $4998(40.6 \%)$ & $4954(43.7 \%)$ \\
\hline
\end{tabular}

ART, assisted reproductive technology; BW, birth weight; HES, Hospital Episode Statistics; HFEA, Human Fertilisation and Embryology Authority; ICSI, intracytoplasmic sperm injection; IMD, Index of Multiple Deprivation; IVF, in vitro fertilisation; NCP, Naturally conceived population control; NCS, Naturally conceived siblings; ONS, Office for National Statistics; SART, ART with siblings.

S6). Moreover, children born after frozen embryo transfers were significantly heavier than those born after fresh embryo transfers (BW difference:-155 g; 95\% CI: -175 to -135$)$.

Family-matched analysis comparing showed that children born after fresh embryo transfers were lighter (BW difference: -57 g; 95\% CI: -75 to -38 ) and those born after frozen embryo transfers were heavier (BW difference: 152 g; $95 \%$ CI: 113 to 190) than the HESNCS group (table 4; online supplemental table S7). Moreover, children born after frozen embryo transfers were significantly heavier than those born after fresh embryo transfers (BW difference: -209 g; 95\% CI: -249 to -168$)$.

\section{DISCUSSION}

This study aimed to substantially enhance the research value of the HFEA register by utilising electronic record linkage methodology to establish a cohort of ART children born in the UK between 1992 and 2009, their NCS and matched NCP controls. Additionally, a subcohort consisting of those born between 1997 and 2009 was also linked to the Hospital Episode Statistics database

Table 4 Statistical analysis of BW

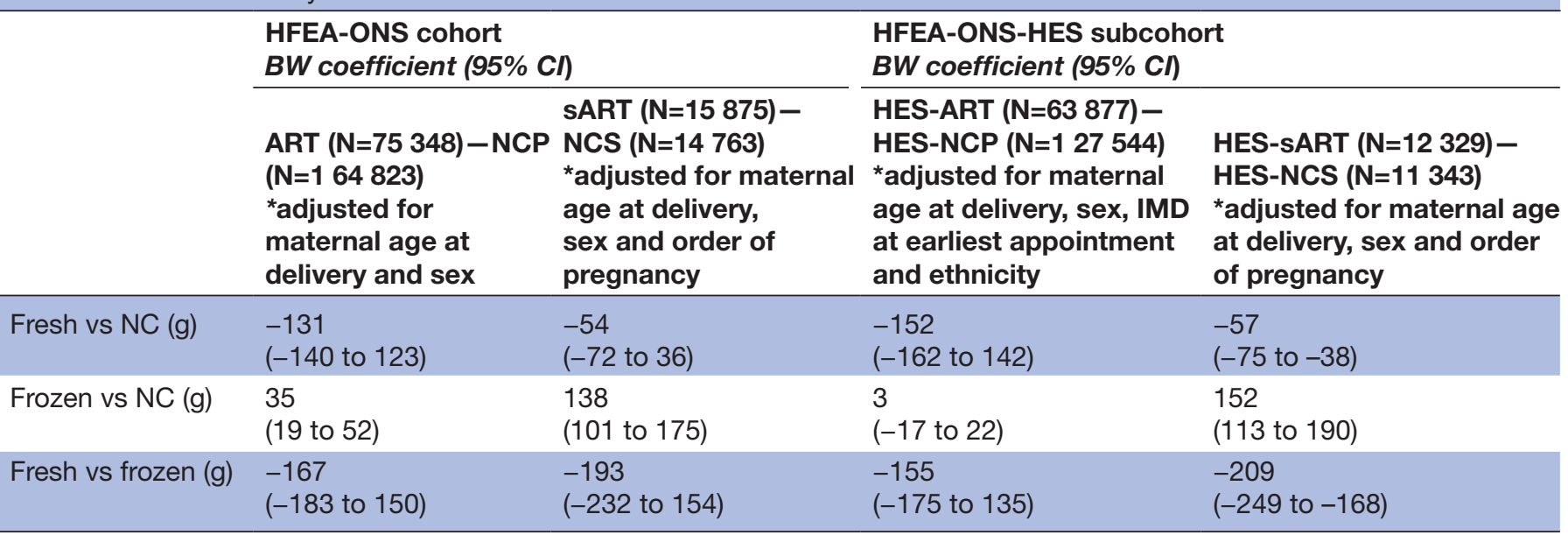

ART, assisted reproductive technology; BW, birth weight; HES, Hospital Episode Statistics; HFEA, Human Fertilisation and Embryology Authority; IMD, Index of Multiple Deprivation; NC, naturally conceived; NCP, Naturally conceived population control; NCS, Naturally conceived siblings; ONS, Office for National Statistics; SART, ART with siblings. 
to allow examination of postnatal health outcomes. The final cohort consisted of 75348 children born after nondonor ART carried out in the UK between 1 April 1992 and 31 July 2009, 14763 NCS and 164823 matched NCP controls. Of these, 63877 ART, 11343 NCS and 127544 matched NCP controls were linked to hospital data up to 2015 , thus providing a valuable resource for comprehensive, non-invasive, continued immediate and longer term health monitoring of this population as they grow up.

An exemplar analysis comparing BW between children born after ART, their NCS and matched NCP controls was also carried out to demonstrate the validity of this cohort. The results of this analysis confirmed the findings of our previous linkage study on a subset of the entire 1992-2009 cohort, ${ }^{39}$ that children born after fresh embryo transfer tended to be lighter and those born from frozen transfer were heavier compared with their NCS and matched NCP controls. These findings are broadly in agreement with numerous large register-based studies and meta-analyses, but add valuable confirmation of the magnitude of $\mathrm{BW}$ differences in a large UK population. ${ }^{1556-64}$ Castillo et $a l^{65}$ reported a similar magnitude of difference to that seen in sibling pairs in a more recent UK cohort, suggesting that the difference in BW between the fresh and frozen embryo transfer groups may not be explained entirely by maternal characteristics and the underlying cause of infertility as these were likely to have remained relatively stable between siblings. Notably, the BW difference observed between frozen transfer and NC babies is much larger in the sibling pair analysis than in the nonsibling comparison and larger than observed by Hann et $a l^{39}$ This merits further investigation, especially as increased rates of macrosomia following frozen transfer are an ongoing concern. ${ }^{3461}$ Other possible explanations include differences in the maternal uterine environment caused by either hormonal stimulation (fresh cycles) or hormonal preparation of the uterus (frozen cycles). ${ }^{66}$ Although lack of appropriate data on the HFEA register prevented exploration of these effects in the current analysis, a recent UK cohort study by Castillo $e t a l^{65}$ using more detailed clinic data reported no association between type of FET and BW. Molecular changes in the early embryo during freezing and thawing might also result in changes in the developmental process leading to altered BW and long-term health. ${ }^{3367-70}$

In the current study, the difference in BW between children born after fresh embryo transfer and those born after natural conception was seen to attenuate markedly from $-131 \mathrm{~g}$ in the population to $-54 \mathrm{~g}$ in the within-sibling analysis. By contrast, the difference in BW between children born after frozen embryo transfer and those born after natural conception was seen to markedly increase from 35 $\mathrm{g}$ in the population to $138 \mathrm{~g}$ in the within-sibling analysis in the same dataset. This suggests that the findings of the within-family analysis must be interpreted with caution, with potential explanatory factors for these differences including subfertility and familial masking confounders in relation to the increase of the association of frozen transfer versus natural conception. Unavailability of birth order data for the population controls prevented us from adjusting for it in the ART versus NCP comparison, and this could plausibly act as a strong confounder given its association with mean BW is stronger than any differences due to ART in most studies. This notable difference between the population and within-family analyses requires further exploration.

Repeating the exemplar analysis using the cohort and subcohort produced by the linkages described above not only increased confidence in the findings but also allowed us to control for potential confounding factors such as maternal age, birth order, socioeconomic status and ethnicity which are known to affect BW. ${ }^{71}$

The cohort described here will allow more effective use of HFEA data for health monitoring and will be of value to researchers from a variety of professional backgrounds. The linked dataset will be returned to the HFEA and access will be controlled by them, although specific ethical approval will be required along with that of the Confidentiality Advisory Group (CAG) of the Health Research Authority (HRA).

In order to provide reliable risk estimates of relatively rare conditions in a specific group of children born after ART, large, well-designed cohort studies, preferably including families, are necessary. However, as it may not always be appropriate to contact these families directly due to the very personal nature of the treatments involved, access to national-level electronically linked data on cohorts such as the current one provides a costeffective, non-intrusive and comprehensive way to answer sophisticated research questions in a wide range of areas.

\section{Strengths and limitations}

The main strength of this study lies in the meticulous linkage of robust, routinely collected administrative health data to yield a large cohort that is nationally unique and complements other similar linked cohorts, such as the Nordic linked cohorts, ${ }^{19}$ thus increasing the generalisability, accuracy and precision of results from subsequent analyses. The research value and quality and consistency of the HFEA cohort 1992-2009 data have been considerably enhanced through linkage to the ONS birth records and HES databases and removal of artefacts and duplicates. Linkage to the hospital admissions and outpatient database provides long-term mortality and morbidity outcome data on offspring and also represents a high-quality cross-sectoral evidence base that can be used for longitudinal research, policy planning and strategic development.

However, there are also several challenges associated with electronic data linkage studies in general, and Harron $e t a l^{72}$ summarised these into three groups, namely those pertaining to the (1) the data linkage environment and privacy preservation; (2) the linkage process itself, which includes data preparation linkage methods; and (3) the linkage quality and potential bias in linked data. In the context of the current study, limitations in the linkage 
process itself included those associated with the method of definition of NC siblings used. The identification of sibling controls would be very sensitive to any errors in linkage, and missed second ART babies would appear as conventional siblings. Parents who had NC children were likely to have been less severely subfertile than parents who did not, and ART children born to the truly infertile would not have conventional siblings. Therefore, the NCS group in this study would have parents with borderline fertility problems or those who developed secondary infertility after the birth of the NC child. For this reason, extensive quality assurance procedures were carried out on the linkage process. With regard to the linkage quality, as this was a bespoke linkage that has never been carried out before, there were no standardised quality assurance measures in place; however, the linkage was extensively checked manually by the team at NHS Digital prior to dissemination for analysis.

The often weak/inaccurate identifier data on the HFEA register and the high threshold for matching used in the current study meant that approximately $23 \%$ of children were lost during the linkage process. This is a limitation as almost $100 \%$ coverage can be achieved in settings with availability of unique identifying numbers for both mother and child. However, although unavailable for the study period explored here, the HFEA now record both the mother and child's NHS number, suggesting that this loss to follow-up may be avoided in future studies. ${ }^{73}$ As HES monitoring data is only available from 1997, children born to women who underwent ART prior to this could not be linked to any hospital records, thus limiting our ability to examine health outcomes in those born before 1997 and exploring the effects of changes in ART techniques on health over that period. However, comparison of maternal age between the unlinked and linked records showed no substantive differences (online supplemental table S8). Unfortunately, unavailability of data prevented us from carrying out further examination and comparison of the educational levels and socioeconomic profile of unlinked records. Nevertheless, linkage of cases born before 1997 to their birth records is still valuable as it may allow investigation of outcomes available on the birth register in the future. Moreover, although these data have been used extensively for research purposes, there have been long-standing concerns regarding the quality, completeness and coverage of HES records within health services and the academic community. ${ }^{74}$

The BW analysis provides an example use of these cohorts and the strengths and limitations of sibling comparisons. However, it cannot be considered as an exhaustive analysis as gestational data was not available for NC children and there is limited covariate data in the present dataset. This is mainly because gestation is not recorded on the birth registration dataset and is of poor quality on the maternal arm of a child's HES record $(>50 \%$ missing). As a result, although the quality of such data for the ART group (accessed from the HFEA register) was good, it was not available for the NCS and
NCP control groups. Further, ART treatment data is available on the HFEA register, which was not included in the current datasets, and these could be extracted for future studies. In particular, the developmental stage of the embryo at transfer and number of embryos transferred are important determinants of treatment success rate (ie, the probability of a child appearing on the HFEA birth register) and also gestation and BW. ${ }^{37} 3965$ Unfortunately, there was no way to systematically identify and account for children born after ART who emigrated or children born to mothers who lived in the England and Wales but travelled abroad for ART treatment, although European estimates of cross-border reproductive care activity suggest that the number of children to whom either of these applies is be small. ${ }^{75}$ Due to lack of maternal data, it was not feasible to identify and exclude NCP controls that were part of a triplet or higher order birth. However, the number of such individuals is estimated to be small as the incidence of naturally occurring triplets is in the range of 1:5000-1:9000. ${ }^{44}$

Lastly, an important limitation of the current cohort is that it finishes in 2009. Given that ART technologies have advanced rapidly in the last 10 years, there is an urgent need to continue to prospectively monitor the next cohort of children from 2010 onwards. Two recent UK studies ${ }^{5665}$ have suggested that BWs from both fresh and frozen transfers are increasing with time and may be different in the post 2010 cohort, suggesting that there may potentially be differences (of unknown origin) in the health outcomes of babies born more recently.

\section{COLLABORATION}

The current study carried out a bespoke record linkage that generated a new child cohort for use in exploring the relationship between conception via ART and short-term and long-term health outcomes in offspring and enabling future linkage studies to other developmental and health data sources.

On completion of our further planned analyses, access to the linked dataset will be controlled by HFEA and NHS Digital and specific ethical approval will be required along with approval from the CAG of the HRA.

\section{Author affiliations}

${ }^{1}$ Population, Policy \& Practice Department, UCL Great Ormond Street Institute of Child Health Population Policy and Practice, London, UK

${ }^{2}$ Division of Population Health, Health Services Research \& Primary Care, University of Manchester, Manchester, UK

${ }^{3}$ Department of Education, University of Oxford, Oxford, UK

${ }^{4}$ Department of Reproductive Medicine, St Mary's Hospital, Manchester, UK

${ }^{5}$ Department of Obstetrics \& Gynaecology, School of Medicine, Dentistry \& Nursing, Reproductive \& Maternal Medicine, University of Glasgow, Glasgow, UK

${ }^{6} \mathrm{MRC}$ Integrative Epidemiology Unit, University of Bristol Bristol Population Health Science Institute, Bristol, UK

${ }^{7}$ Department of Obstetrics, Gynecology, and Reproductive Biology, College of Human Medicine, Michigan State University, East Lansing, Michigan, USA

Contributors In line with the ICMJE authorship guidelines, AS, SAR, DRB, SMN, BL and DL made substantial contributions to the conception or design of the work. AGS 
and MP made substantial contributions to the acquisition of data. MP undertook data preparation and provided statistical analysis, with SAR and JG providing statistical oversight. MP, SAR, JG, DRB, SMN, DL, BL and AS made substantial contributions to the interpretation of data. All authors contributed to the drafting of the manuscript and/or the revising of the manuscript. All authors have given final approval of the version to be published and agree to its accuracy.

Funding This work was supported by the Medical Research Council (Grant number MR/L020335/1)

Competing interests None declared.

Patient consent for publication Not required

Ethics approval Ethical approval and Section 251 support were obtained from the NHS Research Ethics Committee and Confidentiality Advisory Group, respectively. Additional data access permissions were sought from the HFEA Register Research Panel, ONS Micro-Data Release board and the NHS Digital Medical Register. All researchers with data access underwent NHS Digital Data Security Awareness and ONS Safe Researcher accreditation.

Provenance and peer review Not commissioned; externally peer reviewed.

Data availability statement Data may be obtained from a third party and are not publicly available. Deidentified linked cohort data can be accessed from the Human Fertilisation and Embryology Authority and NHS Digital where it will be held with restricted access. Specific ethical approval from the Research Ethics Committee (REC) and the Confidentiality Advisory Group (CAG) of the Health Research Authority (HRA) will be required for access.

Supplemental material This content has been supplied by the author(s). It has not been vetted by BMJ Publishing Group Limited (BMJ) and may not have been peer-reviewed. Any opinions or recommendations discussed are solely those of the author(s) and are not endorsed by BMJ. BMJ disclaims all liability and responsibility arising from any reliance placed on the content. Where the content includes any translated material, BMJ does not warrant the accuracy and reliability of the translations (including but not limited to local regulations, clinical guidelines, terminology, drug names and drug dosages), and is not responsible for any error and/or omissions arising from translation and adaptation or otherwise.

Open access This is an open access article distributed in accordance with the Creative Commons Attribution 4.0 Unported (CC BY 4.0) license, which permits others to copy, redistribute, remix, transform and build upon this work for any purpose, provided the original work is properly cited, a link to the licence is given, and indication of whether changes were made. See: https://creativecommons.org/ licenses/by/4.0/

ORCID iDs

Mitana Purkayastha http://orcid.org/0000-0002-1870-8838

Julian Gardiner http://orcid.org/0000-0001-8988-3812

\section{REFERENCES}

1 Lancaster P, de Mouzon J. Global Committee reproductive art surveillance: monitoring technologies assisted the (ICMART) International. Assisted Reproductive Technology Surveillance 2019;101.

2 Barker DJP. Fetal programming of coronary heart disease. Trends Endocrinol Metab 2002;13:364-8.

3 Lane M, Robker RL, Robertson SA. Parenting from before conception. Science 2014;345:756-60.

4 Fleming TP, Watkins AJ, Velazquez MA, et al. Origins of lifetime health around the time of conception: causes and consequences. Lancet 2018;391:1842-52.

5 Fisher-Jeffes LJ, Banerjee I, Sutcliffe AG. Parents' concerns regarding their ART children. Reproduction 2006;131:389-94.

6 Källén B, Finnström O, Nygren K-G, et al. In vitro fertilization in Sweden: child morbidity including cancer risk. Fertil Steril 2005;84:605-10.

7 Schieve LA, Rasmussen SA, Buck GM, et al. Are children born after assisted reproductive technology at increased risk for adverse health outcomes? Obstet Gynecol 2004;103:1154-63.

8 Reddy UM, Wapner RJ, Rebar RW, et al. Infertility, assisted reproductive technology, and adverse pregnancy outcomes: Executive summary of a national Institute of child health and human development workshop. Obstet Gynecol 2007;109:967-77.

9 Pandey S, Shetty A, Hamilton M, et al. Obstetric and perinatal outcomes in singleton pregnancies resulting from IVF/ICSI: a systematic review and meta-analysis. Hum Reprod Update 2012;18:485-503.

10 Gnoth C, Godehardt E, Frank-Herrmann P, et al. Definition and prevalence of subfertility and infertility. Hum Reprod 2005;20:1144-7.

11 Ceelen M, van Weissenbruch MM, Prein J, et al. Growth during infancy and early childhood in relation to blood pressure and body fat measures at age 8-18 years of IVF children and spontaneously conceived controls born to subfertile parents. Hum Reprod 2009;24:2788-95.

12 Ceelen M, van Weissenbruch MM, Vermeiden JPW, et al. Pubertal development in children and adolescents born after IVF and spontaneous conception. Hum Reprod 2008;23:2791-8.

13 Dumoulin JC, Land JA, Van Montfoort AP, et al. Effect of in vitro culture of human embryos on birthweight of newborns. Hum Reprod 2010;25:605-12.

14 van Montfoort APA, Hanssen LLP, de Sutter P, et al. Assisted reproduction treatment and epigenetic inheritance. Hum Reprod Update 2012;18:171-97.

15 Stormlund S, Sopa N, Zedeler A, et al. Freeze-all versus fresh blastocyst transfer strategy during in vitro fertilisation in women with regular menstrual cycles: multicentre randomised controlled trial. BMJ 2020;370:m2519.

16 Sandin S, Nygren K-G, Iliadou A, et al. Autism and mental retardation among offspring born after in vitro fertilization. JAMA 2013;310:75-84.

17 Bay B, Mortensen EL, Hvidtjørn D, et al. Fertility treatment and risk of childhood and adolescent mental disorders: register based cohort study. BMJ 2013;347:f3978.

18 Davies MJ, Moore VM, Willson KJ, et al. Reproductive technologies and the risk of birth defects. N Engl J Med 2012;366:1803-13.

19 Opdahl S, Henningsen A-KA, Bergh C, et al. Data resource profile: Committee of Nordic assisted reproductive technology and safety (CoNARTaS) cohort. Int J Epidemiol 2020;49:365-6.

20 Henningsen A-KA, Romundstad LIVB, Gissler M, et al. Infant and maternal health monitoring using a combined Nordic database on art and safety. Acta Obstet Gynecol Scand 2011;90:683-91.

21 Wennberg AL, Opdahl S, Bergh C, et al. Effect of maternal age on maternal and neonatal outcomes after assisted reproductive technology. Fertil Steril 2016;106:1142-9. e14.

22 Finnström $\mathrm{O}$, Källén B, Lindam A, et al. Maternal and child outcome after in vitro fertilization - a review of 25 years of population-based data from Sweden. Acta Obstet Gynecol Scand 2011;90:494-500.

23 Henningsen A-KA, Pinborg A, Lidegaard Øjvind, et al. Perinatal outcome of singleton siblings born after assisted reproductive technology and spontaneous conception: Danish national siblingcohort study. Fertil Steril 2011;95:959-63.

24 Kalra SK, Ratcliffe SJ, Barnhart KT, et al. Extended embryo culture and an increased risk of preterm delivery. Obstet Gynecol 2012;120:69-75.

25 Romundstad LB, Romundstad PR, Sunde A, et al. Effects of technology or maternal factors on perinatal outcome after assisted fertilisation: a population-based cohort study. Lance 2008;372:737-43.

26 Lawlor DA, Tilling K, Davey Smith G. Triangulation in aetiological epidemiology. Int J Epidemiol 2017;22:dyw314-86.

27 Romundstad LB, Romundstad PR, Sunde A, et al. Increased risk of placenta previa in pregnancies following IVF/ICSI; a comparison of art and non-ART pregnancies in the same mother. Hum Reprod 2006;21:2353-8.

28 Human Fertilisation and Embryology Authority. Fertility treatment 2014-2016 trends and figures. London: HFEA, 2018. https://www. hfea.gov.uk/media/3188/hfea-fertility-trends-and-figures-2014-2016. pdf

29 Human Fertilisation and Embryology Act 1990 (UK). Available: https:// www.legislation.gov.uk/ukpga/1990/37/contents

30 Human fertilisation and embryology privacy policy, 2018. Available: https://www.hfea.gov.uk/privacy-policy-cookies-and-accessibility/ privacy-policy/

31 Human Fertilisation \& Embryology Authority, 2019. Available: https:// www.hfea.gov.uk/

32 Templeton A, Morris JK, Parslow W. Factors that affect outcome of in-vitro fertilisation treatment. Lancet 1996;348:1402-6.

33 Nelson SM, Lawlor DA. Predicting live birth, preterm delivery, and low birth weight in infants born from in vitro fertilisation: a prospective study of 144,018 treatment cycles. PLoS Med 2011;8:e1000386.

34 Maheshwari A, Raja EA, Bhattacharya S. Obstetric and perinatal outcomes after either fresh or thawed frozen embryo transfer: an analysis of 112,432 singleton pregnancies recorded in the human fertilisation and embryology authority anonymized dataset. Fertil Steril 2016;106:1703-8. 
35 Kamath MS, Antonisamy B, Selliah HY, et al. Perinatal outcomes of singleton live births with and without vanishing twin following transfer of multiple embryos: analysis of 113784 singleton live births. Hum Reprod 2018;33:2018-22.

36 Marconi N, Raja EA, Bhattacharya S, et al. Perinatal outcomes in singleton live births after fresh blastocyst-stage embryo transfer: a retrospective analysis of 67147 IVF/ICSI cycles. Hum Reprod 2019;34:1716-25.

37 Castillo CM, Johnstone ED, Horne G, et al. Associations of IVF singleton birthweight and gestation with clinical treatment and laboratory factors: a multicentre cohort study. Hum Reprod 2020;35:2860-70.

38 Roberts SA, McGowan L, Hirst WM, et al. Towards single embryo transfer? modelling clinical outcomes of potential treatment choices using multiple data sources: predictive models and patient perspectives. Health Technol Assess 2010;14:1-237.

39 Hann M, Roberts SA, D'Souza SW, et al. The growth of assisted reproductive treatment-conceived children from birth to 5 years: a national cohort study. BMC Med 2018;16:224.

40 Human Fertilisation \& Embryology Act 2008. (UK). Available: https:// www.legislation.gov.uk/ukpga/2008/22/contents

41 Williams CL, Bunch KJ, Stiller CA, et al. Cancer risk among children born after assisted conception. N Engl J Med 2013;369:1819-27.

42 Human Fertilisation and Embryology Authority. Fertility treatment 2018: trends and figures. Available: https://www.hfea.gov.uk/ about-us/publications/research-and-data/fertility-treatment-2018trends-and figures/\#: :text=Birth\%20rates\%20from\%20IVF\%20 have,HFEA\%20was\%20established\%20in\%201991

43 Human Fertilisation and Embryology Authority. Fertility treatment 2018: trends and figures quality and methodology report. Available: https://www.hfea.gov.uk/about-us/publications/research-and-data/ fertility-treatment-2018-trends-and-figures/fertility-treatment-2018quality-and-methodology-report/

44 Office for National Statistics. User quide to birth statistics, 2019 Available: https://www.ons.gov.uk/peoplepopulationandcommunity/ birthsdeathsandmarriages/livebirths/methodologies/userguidetobirth statistics

45 NHS Digital. Hospital episode statistics. Available: https://digital. nhs.uk/data-and-information/data-tools-and-services/data-services/ hospital-episode-statistics

46 Great Britain, National Audit Office, Great Britain, Parliament. House of Commons. Healthcare across the UK: a comparison of the NHS in England, Scotland, Wales and Northern Ireland. The Stationery Office, 2012.

47 The Private Healthcare Information Network. Annual report 2016-17. Available: https://apicms.phin.org.uk/Content/Resource/158-PHIN_ AR_2016-17.pdf

48 Herbert A, Wijlaars L, Zylbersztejn A, et al. Data resource profile: Hospital episode statistics admitted patient care (Hes APC). Int $J$ Epidemiol 2017;:46:1093.

49 Boyd A, Cornish R, Johnson L. Understanding Hospital episode statistics (HES). London, UK: CLOSER, 2017.

50 Smith T, Noble M, Noble S. The English indices of deprivation 2015. London: Department for Communities and Local Government, 2015.

51 Zegers-Hochschild F, Adamson GD, Dyer S, et al. The International glossary on infertility and fertility care, 2017. Fertil Steril 2017;108:393-406.

52 Williams CL, Jones ME, Swerdlow AJ, et al. Risks of ovarian, breast, and corpus uteri cancer in women treated with assisted reproductive technology in Great Britain, 1991-2010: data linkage study including 2.2 million person years of observation. BMJ 2018;362:k2644.

53 Yokoyama Y, Shimizu T, Hayakawa K. Incidence of handicaps in multiple births and associated factors. Acta Genet Med Gemellol 1995; 44:81-91.

54 Doyle P. The outcome of multiple pregnancy. Hum Reprod 1996:11:110-20.

55 von Elm E, Altman DG, Egger M, et al. Strengthening the reporting of observational studies in epidemiology (STROBE) statement: guidelines for reporting observational studies. BMJ 2007;335:806-8.
56 Castillo CM, Horne G, Fitzgerald CT, et al. The impact of IVF on birthweight from 1991 to 2015: a cross-sectional study. Hum Reprod 2019;34:920-31.

57 Pelkonen S, Koivunen R, Gissler M, et al. Perinatal outcome of children born after frozen and fresh embryo transfer: the Finnish cohort study 1995-2006. Hum Reprod 2010;25:914-23.

58 Roy TK, Bradley CK, Bowman MC, et al. Single-Embryo transfer of vitrified-warmed blastocysts yields equivalent live-birth rates and improved neonatal outcomes compared with fresh transfers. Fertil Steril 2014;101:1294-301.

59 Litzky JF, Boulet SL, Esfandiari N, et al. Effect of frozen/thawed embryo transfer on birthweight, macrosomia, and low birthweight rates in US singleton infants. Am J Obstet Gynecol 2018;218:433. e1-10.

60 Berntsen S, Pinborg A. Large for gestational age and macrosomia in singletons born after frozen/thawed embryo transfer (FET) in assisted reproductive technology (art). Birth Defects Res 2018;110:630-43.

61 Terho AM, Pelkonen S, Opdahl S, et al. High birth weight and large-for-gestational-age in singletons born after frozen compared to fresh embryo transfer, by gestational week: a Nordic register study from the CoNARTaS group. Human Reproduction 2021;36:1083-92.

62 Elias FTS, Weber-Adrian D, Pudwell J, et al. Neonatal outcomes in singleton pregnancies conceived by fresh or frozen embryo transfer compared to spontaneous conceptions: a systematic review and meta-analysis. Arch Gynecol Obstet 2020;302:31-45.

63 Maheshwari A, Pandey S, Amalraj Raja E, et al. Is frozen embryo transfer better for mothers and babies? Can cumulative metaanalysis provide a definitive answer? Hum Reprod Update 2018;24:35-58.

64 Sha T, Yin X, Cheng W, et al. Pregnancy-related complications and perinatal outcomes resulting from transfer of cryopreserved versus fresh embryos in vitro fertilization: a meta-analysis. Fertil Steril 2018;109:330-42.

65 Castillo CM, Harper J, Roberts SA, et al. The impact of selected embryo culture conditions on art treatment cycle outcomes: a UK national study. Hum Reprod Open 2020;2020:hoz031.

66 Berntsen S, Söderström-Anttila V, Wennerholm U-B, et al. The health of children conceived by ART: 'the chicken or the egg?'. Hum Reprod Update 2019;25:137-58.

67 Luke B, Brown MB, Wantman E, et al. Increased risk of large-forgestational age birthweight in singleton siblings conceived with in vitro fertilization in frozen versus fresh cycles. J Assist Reprod Genet 2017;34:191-200.

68 Henningsen A-KA, Pinborg A. Birth and perinatal outcomes and complications for babies conceived following art. Semin Fetal Neonatal Med 2014;19:234-8.

69 Pinborg A. To transfer fresh or thawed embryos? Semin Reprod Med 2012;30:230-5

70 Kimber SJ, Sneddon SF, Bloor DJ, et al. Expression of genes involved in early cell fate decisions in human embryos and their regulation by growth factors. Reproduction 2008;135:635-47.

71 Goldstein H. Factors related to birth weight and perinatal mortality. Br Med Bull 1981;37:259-64.

72 Harron K, Dibben C, Boyd J, et al. Challenges in administrative data linkage for research. Big Data Soc 2017;4:205395171774567.

73 Human Fertilisation and Embryology Authority. How we manage your information. Available: https://www.hfea.gov.uk/choose-aclinic/how-we-manage-your-information/\#: :text=Key\%20facts\% 20Researchers\%20need\%20your,not\%20publish\%20your\% 20identifying\%20information

74 Spencer SA, Davies MP. Hospital episode statistics: improving the quality and value of hospital data: a national Internet esurvey of hospital consultants. BMJ Open 2012;2. doi:10.1136/ bmjopen-2012-001651. [Epub ahead of print: 1911 2012]

75 Shenfield F, de Mouzon J, Pennings G, et al. Cross border reproductive care in six European countries. Hum Reprod 2010;25:1361-8. 